\title{
Evidence of High Frequency Gravity Wave Forcing on the Meridional Residual Circulation at the Mesopause Region
}

\author{
Fabio Vargas ${ }^{\mathrm{a}, *}$, Gary Swenson ${ }^{\mathrm{a}}$, Alan Liu ${ }^{\mathrm{b}}$ \\ ${ }^{a}$ University of Illinois at Urbana-Champaign, $306 \mathrm{~N}$ Wright St, Urbana, IL 61801, USA, \\ Tel: +12173336982 \\ ${ }^{b}$ Embry-Riddle Aeronautical University, 600 South Clyde Morris Boulevard, Daytona \\ Beach, FL 32114, USA, Tel: +1386 226 6538
}

\begin{abstract}
Data of high frequency gravity wave propagation direction from globally distributed stations indicate a meridional preference for the mesospheric gravity waves to be globally oriented toward the summer pole. This is opposite to the mean residual circulation (summer to winter) at mesospheric altitudes. We discuss here a number of dynamic considerations including filtering that may be responsible for the preferential wave orientation, and the effect of the gravity wave forcing imposed on the meridional flow due to dissipative waves. Using nightglow image data recorded in three distinct latitude stations, we have estimated the meridional wave drag (i.e, deceleration) of about $-4.6 \pm 0.2 \mathrm{~m} / \mathrm{s} /$ day during the summer, and $3.8 \pm 0.2 \mathrm{~m} / \mathrm{s} /$ day during the winter, which is significant because the meridional flow has small magnitude. This is a component of dynamic forcing in the mesopause region, not heretofore recognized.
\end{abstract}

Keywords: Residual Meridional Circulation; Gravity waves; Wave Drag; Nightglow;

\footnotetext{
${ }^{*}$ Corresponding author

Email addresses: fvargas@illinois.edu (Fabio Vargas), swenson1@illinois.edu (Gary Swenson), alan.liu@erau.edu (Alan Liu)
}

Preprint submitted to Advances in Space Research

July 29, 2015

(C) 2015. This manuscript version is made available under the Elsevier user license http://www.elsevier.com/open-access/userlicense/1.0/ 


\section{Introduction}

The Meridional Residual Circulation (MRC) is the result of the interhemisphere thermal gradient caused by a middle atmosphere out of radiative balance due to mechanical wave forcing (Houghton, 1978; Solomon et al., 1987). Postulated by Brewer (1949), the MRC explains the high concentration of ozone and water vapor at high latitudes even the production is larger at low latitude due to the higher solar illumination.

In the lower atmosphere, the meridional circulation is composed of two circulation cells below the tropopause, with upwelling (downwelling) of air parcels at the equator (poles), and travel from equator to pole to close the loop. Near the mesopause, the MRC is a single cell structure, presenting air upwelling in the summer pole and downwelling in the winter pole, and a residual flow from pole to pole at those altitudes closing the circuit (e.g., Yue and Liu, 2010). The MRC has mean absolute magnitude of $5-25 \mathrm{~m} / \mathrm{s}$ during solstices, which follows from climatologies obtained from satellite measurements (McLandress et al., 1996). Also, the Zhu et al. (1997) model showed MRC magnitudes of $\sim 25 \mathrm{~m} / \mathrm{s}$ around $92 \mathrm{~km}$, with maximum in the summer mesopause.

The dominant mechanism driving the atmosphere out of radiative equilibrium is the dissipation and breaking of gravity waves $(\mathrm{GW})$. The $\mathrm{GW}$ momentum deposition (i.e., the flux divergence, wave acceleration, or wave drag) could reach $\sim 100 \mathrm{~m} / \mathrm{s} /$ day, as estimated through rocket observations (Lindzen, 1981). The influence of gravity waves on the background zonal flow in the stratosphere is relatively well understood, and has been parameterized (e.g., Holton and Zhu, 1984; Zhu et al., 2010), and included in Global Circulation Models (GCM) such as the Thermosphere Ionosphere Mesosphere Electrodynamics General Circulation Model (TIME-GCM). The model proposed by Zhu et al. (1997) is consistent with meridional velocities of $20-30 \mathrm{~m} / \mathrm{s}$ measured by the Upper Atmosphere Research Satellite (UARS), and supports a mesosphere forced by breaking/dissipating gravity waves. However, a finetuning of the parameterization schemes is still an important subject for the modeling community (e.g., Hoffmann et al., 2010). In fact, there is evidence of significant departures from modeled winds, predicted by current global circulation models. For example, the meridional circulation strength estimated by TIME-GCM is inconsistent with observations of the fast transport of water plumes released during rocket lunches (Yue and Liu, 2010), which presented rapid displacements at velocities of $35-40 \mathrm{~m} / \mathrm{s}$. As observed by Yue 
and Liu (2010), tides and planetary waves can be responsible for departures from the means at those altitudes.

It is now well understood that high frequency (HF) gravity waves (period $\lesssim 1$ hour) propagating from the lower atmosphere into the mesosphere carry significant momentum (e.g., Zhang et al., 2014), and, when damped, transfer that momentum to the mean flow. Also it is well understood that the strong zonal circulation filters the waves, as shown in very early dynamic studies. The strong stratospheric westerlies in the winter remove the westerly propagating waves preventing them from reaching the mesosphere. The opposite is true for the summer, when the strong stratospheric easterlies transmit only the westerly propagating waves into the mesosphere.

We have observational evidence of $\mathrm{HF}$ waves observed in the mesospheric airglow layers from a number of stations around the globe. These waves have been studied and segregated into their directional trends for summer and winter. The data set shows, however, that the meridional component of waves reaching the mesopause region have a preponderant orientation toward the summer pole. Note there is no strong filter for the meridional waves in the stratospheric wind pattern.

In this paper, we discuss how HF gravity waves observed in nightglow images show a persistent horizontal wave propagation into the $\mathrm{MRC}$, and also discuss which dynamic mechanisms are the causes of such GW orientation. We also discuss how GW would drive the meridional flow around the mesosphere and lower thermosphere altitudes. Finally, we estimate GW forcing magnitude on the meridional flow by using nightglow image data recorded at three stations (two in Brazil and one in Chile). The objective of this paper is to bring our conclusions to the attention of the upper atmospheric dynamics community and to discuss the likely effects which are not currently contained in dynamic models to the circulation. This meridional high frequency gravity wave effect is less recognized than that in the zonal direction, but not less important, and requires further investigation.

\section{The Meridional Component Vector of GW at the Mesosphere}

Several studies have addressed the directionality of the gravity wave field observed through nightglow imaging. Table 1 presents several references used to access the directionality of high frequency GW in nightglow images. The data was taken from stations with seasonally relevant data. The references 
are sorted by low, mid, and high latitude. The emissions recorded in a particular location, the date of the observations, and the number of nights in which measurements made under clear observation conditions are also given. The station index posted in column nine is defined as the number of observational nights in each site divided by the number of months necessary to perform those measurements under clear skies and good weather conditions.

We have sorted the papers as long, medium, or short term studies with the idea of ranking each study by its statistical strength, and showed the predominant meridional component vector of GW observed in each of them. Short term studies present a nightglow dataset of less than 6 months long, and medium term studies have a dataset of 6 to 18 months, respectively. Long-term climatologies are those with more than 18 months of image data.

Fig. 1 shows a world map and the geographical distribution of stations around the globe as given in Table 1. Fig. 1a refers to the northern hemisphere winter, and Fig. 1b refers to the northern hemisphere summer. The net horizontal orientation of the wave field is represented by the zonal and meridional arrow components placed at the geographical position of each station. The size of each arrow is proportional to the percentage of net wave field propagating in a specific direction for the time length of a given study. For simplicity, three arrow lengths were defined: arrows having three length units represent a large number of GW moving in that direction (>70\%); two length unit arrows represent $30 \%$ to $70 \%$ of the waves moving in the given direction; one length unit arrows express less than 30\% waves with that orientation. No arrow on a given station indicates that no data was available there. Only solstice data is present in Fig. 1.

Notice that long-term climatologies obtained from several stations have provided good understanding of spatial and temporal scales of GW as well as their seasonal propagation direction to the summer pole. Short and mid term observation campaigns also support this prevalent GW motion.

Fig. 2 presents a meridional cross-section (latitude vs. altitude) of the (a) zonal and (b) meridional background wind for June of 2009 taken from the Horizontal Wind Model 93 (HWM93) (Hedin et al., 1991), corresponding to the northern hemisphere summer. The maximum zonal velocity is $\sim 75 \mathrm{~m} / \mathrm{s}$ at the stratosphere. The stratospheric zonal wind is westward in the northern hemisphere summer, and eastward in the southern hemisphere (Fig. 2a). On the other hand, the meridional wind is much weaker than the zonal wind throughout $0-100 \mathrm{~km}$ range, reaching its maximum of $\sim-30 \mathrm{~m} / \mathrm{s}$ around mid latitudes at mesospheric altitudes (Fig. 2b). 
During summer solstices, we observe an easterly flow, and a westerly flow during the winter solstice. It is well known the zonal flow filters out a portion of the GW spectrum propagating from the troposphere to the mesosphere. Thus, the angular spectrum of GW has a dominant anisotropy during solstices that depends basically on the season and is opposite to the stratospheric wind. The zonal component vector of GW in Fig. 1 is consistent with zonal wind filtering of GW in the stratosphere once the zonal wave motion is preferentially westward in the northern winter, and eastward in the southern summer for most sites. This zonal filtering condition breaks down at some specific locations (e.g. Kototabang, Indonesia), most likely due to local wave sources nearby (Suzuki et al., 2009b), but generally holds true for most of the stations. During the equinoxes, the zonal wind is weaker at the stratosphere, and the GW filtering is not as effective as during the solstices, resulting in a more isotropic wave field observed at higher altitudes.

The meridional component vector of GW in Fig. 1 is mostly poleward (equatorward) during the summer (winter), and equatorward (poleward) during the winter (summer) in the northern (southern) hemisphere. Notice the remarkable feature of the GW meridional component vector (vertical arrows) showing a persistent orientation to the summer pole opposite to the direction of the MRC (from summer to winter). This characteristic is observed in both northern hemisphere winter and summer. The mechanisms driving the meridional component vector of $\mathrm{GW}$ to the summer pole must be ubiquitous and have not been shown in a global picture as that presented here.

Assuming that tropospheric sources are isotropic in the sense that generated waves are radiated to any possible direction, the meridional component vector of GW should be then equally partitioned in equatorward and poleward oriented waves. However, Fig 1 shows clearly that the orientation of the wave field from the winter to the summer pole is widely dominant. Only during the summer in Calgary, Tirunelveli, and Tanjugsari we observe a departure from the dominant meridional wave orientation. As discussed in the studies using image data from those three stations, the peculiar wave orientation was caused by local convective sources nearby those specific observatories. We discuss next what feasible mechanisms would be driving that GW orientation characteristic. 


\section{Causes of the Meridional Orientation of GW}

The relative position of convective wave sources to the observation stations would give clues about the preferential meridional wave orientation. Fig. 3 shows a global picture of the lightning activity associated with tropospheric convection forcing of GW from cumulonimbus clouds during the winter and summer of 1999 obtained by the Optical Transient Detector (OTD) satellite developed by the National Aeronautics and Space Administration (NASA). The picture is also representative of the lightning activity for the years of 1995, 1996, 1997, 1998 and 1999 for both winter and summer, being a proxy of gravity wave convective sources throughout the globe (e.g., Fritts et al., 2006). The lightning activity is larger during the summer, in both hemispheres.

Convective sources are likely the most effective sources of waves that would propagate up to the mesosphere (Fritts et al., 2006). If the radiated waves became trapped in their vertical path, then they would be able to travel large horizontal distances, and then be detectable in stations far away from the original source (e.g., Walterscheid et al., 1999; Hecht et al., 2004). However, because convection radiates $\mathrm{GW}$ isotropically, some other mechanism must be acting in order to explain the highly dominant wave propagation to the summer pole from low latitude sources. That is, the relative positioning of wave sources relative to the observation stations can not explain the GW preferential orientation to the summer pole.

Waves propagating opposite to the summer pole could somehow be removed from the wave field by filtering due to the meridional wind in a similar fashion to that of the zonal wind. However, the meridional wind is weak, having significant magnitude $(\sim 30 \mathrm{~m} / \mathrm{s})$ only at mid latitudes around 90 $100 \mathrm{~km}$ height (Fig. 2b). This way, the meridional wind would not be an effectively filter waves because high frequency GW observed in airglow images usually present large phase velocities $(\gtrsim 40 \mathrm{~m} / \mathrm{s})$. The meridional wind offers a path to GW into the MRC because it is weak and not capable of blocking the waves in their way by filtering. Consequently, it is unlike to be responsible for the persistent meridional direction of the GW.

Above the stratosphere, tidal wave modes have magnitudes that would be consistent with GW filtering in the mesosphere, giving a feasible mechanism that could explain the meridional motion of GW around the globe. However, tidal phases and amplitudes would have to be highly homogeneous around the globe to permit only gravity waves moving toward the summer pole to 
survive to this filtering mechanism, which is also very unlikely. Also, from our image data set, another evidence against tidal filtering is based on the fact that GW observed simultaneously in images of different nightglow layers frequently present very similar orientation. If tidal winds would be filtering waves between layers separated in altitude, then the wave field orientation would not have similar orientation characteristics.

Likewise, it has been anticipated from gravity wave studies supporting the residual circulation that zonally directed waves emerging from the stratospheric filtering reach the mesosphere, applying zonal stress when they break or dissipate. Examination of the angular pattern of the wave direction climatology from studies by Tang et al. (2005) and Li et al. (2011b) would suggest that the propagation direction was prevalent in the middle stratosphere, by the time the waves have reached the mesopause, the angular spectrum would be rotated by $\sim 60^{\circ}$ clockwise for the respective season (and hemisphere). We have also considered how the horizontal wind shear could impose rotation to the parcel and verified that it would cause a clockwise rotation of phase fronts as well. Also, the shear magnitude is too small to induce this kind of rotation for HF waves, whose transit exposure time to the shear would be on the order of an hour through the middle atmosphere.

The most likely explanation for the meridional wave orientation is that given by Walterscheid et al. (1999). The wave propagation direction is influenced by the mean flow and by the temperature structure of the mesosphere. In fact, Walterscheid et al. (1999) show substantial evidence that quasi-monochromatic GW are most likely trapped in the Lower Thermosphere Duct (LTD), being able to travel long distances. The LTD structure coupled with the zonal wind regime during solstices would create good conditions for poleward (equatorward) oriented waves during the summer (winter) to propagate, while suppressing waves having other orientations. In addition, the penetration conditions created by the LTD would be global and consistent with the winter/summer altitude of the LTD during those seasons.

In a sense of wave influence, the new consideration is that indeed, the zonal component vector of GW reaching the mesopause region imposes a stress, which coupled with the Coriolis force, sets up the residual circulation (summer to winter flow), and the residual circulation in turn, offers a channel for the meridional propagating waves to, in turn, apply a meridional stress to slow down that meridional flow. 


\section{Estimation of the Meridional Drag due to Breaking/Dissipating GW}

Because dissipative waves are dominant in the mesosphere and low thermosphere region (e.g., Tang et al., 2005), they are expected to force the background flow, which results in deceleration. We have measured the magnitude of the high frequency GW drag based on image analysis and GW parameter estimation given in Liu and Swenson (2003); Tang et al. (2005); Vargas et al. (2007, 2009). Evidence of the wave influence in the mesophere and lower thermosphere region is associated, for example, with the downward wave-induced fluxes as measured by Gardner and Liu (2010).

We have airglow image data of the $\mathrm{OH}$ and the $\mathrm{O}\left({ }^{1} S\right)$ emissions obtained in three stations: Cariri, Brazil $\left(7^{\circ} \mathrm{S}\right)$ (two years of data), Cachoeira Paulista, Brazil $\left(23^{\circ} \mathrm{S}\right)$ (four years of data), and Cerro Pachon, Chile $\left(30^{\circ} \mathrm{S}\right)$ (two years of data). The wave flux divergence (or wave drag magnitude) is essentially given by:

$$
D=-\frac{1}{\bar{\rho}} \frac{\partial(\bar{\rho} F)}{\partial z}=-\frac{1}{\bar{\rho}}\left(\frac{\partial \bar{\rho}}{\partial z} F+\frac{\partial F}{\partial z} \bar{\rho}\right)
$$

where $\bar{\rho}$ is the background density and $F$ the momentum flux of a given wave event (see Vargas et al. (2007) and Vargas et al. (2009) for further details of $D$ estimation). In this specific study, we have calculated $D$ between the $O H$ $(87 \mathrm{~km})$ and $O\left({ }^{1} S\right)(96 \mathrm{~km})$ layers only because these layers hardly overlap in altitude.

Estimations of $D$ for the available dataset are presented in Fig. 4 for all three stations. The charts are sorted from lower (top) to higher (bottom) latitude. Each chart presents the flux divergence vs. wave orientation for each season, and shows explicitly the wave preferential meridional component oriented from winter to summer pole. Waves propagating eastward, northward, westward, and southward have orientation of of $0^{\circ}, 90^{\circ}, 180^{\circ}$, and $270^{\circ}$, respectively. The arrows have units of $\mathrm{m} / \mathrm{s} /$ hour. Summer data in Cachoeira Paulista is sparser due to the rainy season occurring from December to January at that location. The higher wave activity density at Cerro Pachon is a result of 300 days of cloudless skies per year.

To summarize the results of Fig. 4, the averaged wave drag and its uncertainty is presented in Table 2 for summer, winter, and equinox, respec-

tively. The values in Table 2 refer only to the meridional component vector of GW (northward). Negative (positive) values indicate southward (northward) 
wave drag. Large uncertainty in $D$ estimations $(>100 \%)$ are not shown in Table 2 .

During the equinoxes, we have found that the mean drag imposed by GW is very small once the angular spectrum of GW is more isotropic. On the other hand, the mean drag is $3.8 \pm 0.2(-4.6 \pm 0.2) \mathrm{m} / \mathrm{s} /$ day during the winter (summer). This is clearly a result of the wave preferential orientation (from the winter to the summer pole) during those seasons. This GW drag is large enough and could possibly counterbalance (or even reverse) the MRC, being this scenario globally valid.

\section{Summary}

We have shown in this paper evidence of a preferential propagation direction of high frequency gravity waves in the mesopause region to the summer pole and into the residual meridional circulation as global trend, in both hemispheres. This effect is real and has been shown in nightglow image data collected in several stations distributed globally during more than 10 years.

The mechanism driving the directionality of gravity waves to the summer pole is not well understood. Likely the meridional winds at lower altitudes offer a propagation path to gravity waves into the meridional residual circulation. The gravity waves, in turn, apply stress to limit that meridional summer-winter wind circulation. We have estimated the wave drag as $-4.6 \pm 0.2 \mathrm{~m} / \mathrm{s} /$ day during the summer and $3.8 \pm 0.2 \mathrm{~m} / \mathrm{s} /$ day during the winter from nightglow image data of three observation stations in South America.

Because the magnitude of the MRC is small $(5-25 \mathrm{~m} / \mathrm{s})$ and oriented to the winter hemisphere, the estimated gravity wave drag would possibly offset (perhaps reverse) the mean meridional wind, or contribute to the return circulation at higher altitudes, in a similar fashion that occurs in the zonal direction. In case the meridional wave drag magnitude is nonzero globally, we also suggest a larger magnitude of the residual meridional circulation than that reported in the literature. Therefore, it is necessary to compare the parameterized GW forcing with the observations in order to obtain reliable estimations of the global circulation in the mesosphere an lower thermosphere region.

\section{Acknowledgement}

We acknowledge Dr. Delano Gobbi and Dr. Paulo Prado Baptista, both from INPE, who have allowed us to use four (two) years of image and meteor 
radar data from Cachoeira Paulista (Cariri). Likewise, we want to acknowledge Dr. Steve Franke from University of Illinois at Urbana-Champaign who have shared the meteor radar data from Cerro Pachon. Many thanks to three unknown reviewers for their valuable comments about this paper. This work has been supported by the National Science Foundation under Grant \# 11-36208 and Grant \# 11-15725.

\section{References}

J. V. Bageston. Caracterização de ondas de gravidade mesosféricas na Estação Antártica Comandante Ferraz (Characterization of mesospheric gravity waves over Comandante Ferraz antarctic station). PhD thesis, Instituto Nacional de Pesquisas Espaciais (National Institute for Space Research), INPE, Sao Jose dos Campos, Brazil, 2009. URL http: //urlib.net/8JMKD3MGP7W/36FCLLE.

A. W. Brewer. Evidence for a world circulation provided by the measurements of helium and water vapour distribution in the stratosphere. Quarterly Journal of the Royal Meteorological Society, 75(326):351-363, 1949. ISSN 1477-870X. doi: 10.1002/qj.49707532603. URL http://dx.doi.org/10 . 1002/qj . 49707532603.

F. Ding, H. Yuan, W. Wan, I. M. Reid, and J. M. Woithe. Occurrence characteristics of medium-scale gravity waves observed in oh and oi nightglow over Adelaide $\left(34.5^{\circ} \mathrm{S}, 138.5^{\circ} \mathrm{E}\right)$. Journal of Geophysical Research: Atmospheres, 109(D14):n/a-n/a, 2004. ISSN 2156-2202. doi: 10.1029/ 2003JD004096. URL http://dx.doi.org/10.1029/2003JD004096.

Xiankang Dou, Tao Li, Yihuan Tang, Jia Yue, Takuji Nakamura, Xianghui Xue, Bifford P. Williams, and Chiao-Yao She. Variability of gravity wave occurrence frequency and propagation direction in the upper mesosphere observed by the $\mathrm{OH}$ imager in northern Colorado. Journal of Atmospheric and Solar-Terrestrial Physics, 72(5-6):457 - 462, 2010. ISSN 13646826. doi: http://dx.doi.org/10.1016/j.jastp.2010.01.002. URL http:// wWw.sciencedirect.com/science/article/pii/S1364682610000131.

M. K. Ejiri, K. Shiokawa, T. Ogawa, K. Igarashi, T. Nakamura, and T. Tsuda. Statistical study of short-period gravity waves in $\mathrm{OH}$ and OI nightglow images at two separated sites. Journal of Geophysical Research: 
Atmospheres, 108(D21):n/a-n/a, 2003. ISSN 2156-2202. doi: 10.1029/ 2002JD002795. URL http://dx.doi.org/10.1029/2002JD002795.

P. J. Espy, G. O. L. Jones, G. R. Swenson, J. Tang, and M. J. Taylor. Seasonal variations of the gravity wave momentum flux in the antarctic mesosphere and lower thermosphere. Journal of Geophysical Research: Atmospheres, 109(D23):n/a-n/a, 2004. ISSN 2156-2202. doi: 10.1029/2003JD004446. URL http://dx.doi.org/10.1029/2003JD004446.

P. J. Espy, R. E. Hibbins, G. R. Swenson, J. Tang, M. J. Taylor, D. M. Riggin, and D. C. Fritts. Regional variations of mesospheric gravity-wave momentum flux over Antarctica. Annales Geophysicae, 24(1):81-88, 2006. doi: 10.5194/angeo-24-81-2006. URL http: //www . ann-geophys . net/24/ $81 / 2006 /$.

David C. Fritts, Sharon L. Vadas, Kam Wan, and Joseph A. Werne. Mean and variable forcing of the middle atmosphere by gravity waves. Journal of Atmospheric and Solar-Terrestrial Physics, 68(3-5):247 - 265, 2006. ISSN 1364-6826. doi: http://dx.doi.org/10.1016/j.jastp.2005. 04.010. URL http://www.sciencedirect.com/science/article/pii/ S1364682605002397.

Chester S. Gardner and Alan Z. Liu. Wave-induced transport of atmospheric constituents and its effect on the mesospheric Na layer. Journal of Geophysical Research: Atmospheres, 115(D20):n/a-n/a, 2010. ISSN 21562202. doi: 10.1029/2010JD014140. URL http://dx.doi.org/10.1029/ 2010 JD014140.

D.H. Giers, Y. Sahai, L.L. Cogger, and E.H. Ryan. Occurrence characteristics of mesospheric gravity waves at $51^{\circ} \mathrm{N}$. Journal of Atmospheric and Solar-Terrestrial Physics, 59(10):1197 - 1203, 1997. ISSN 1364-6826. doi: http://dx.doi.org/10.1016/S1364-6826(96)00117-4. URL http:// wWw.sciencedirect.com/science/article/pii/S1364682696001174.

J. H. Hecht, R. L. Walterscheid, M. P. Hickey, and S. J. Franke. Climatology and modeling of quasi-monochromatic atmospheric gravity waves observed over Urbana, Illinois. Journal of Geophysical Research: Atmospheres, 106 (D6):5181-5195, 2001. ISSN 2156-2202. doi: 10.1029/2000JD900722. URL http://dx.doi .org/10.1029/2000 JD900722. 
J. H. Hecht, S. Kovalam, P. T. May, G. Mills, R. A. Vincent, R. L. Walterscheid, and J. Woithe. Airglow imager observations of atmospheric gravity waves at Alice Springs and Adelaide, Australia during the Darwin area wave experiment (DAWEX). Journal of Geophysical Research: Atmospheres, 109(D20):n/a-n/a, 2004. ISSN 2156-2202. doi: 10.1029/ 2004JD004697. URL http://dx.doi.org/10.1029/2004JD004697.

A. E. Hedin, M. A. Biondi, R. G. Burnside, G. Hernandez, R. M. Johnson, T. L. Killeen, C. Mazaudier, J. W. Meriwether, J. E. Salah, R. J. Sica, R. W. Smith, N. W. Spencer, V. B. Wickwar, and T. S. Virdi. Revised global model of thermosphere winds using satellite and groundbased observations. Journal of Geophysical Research: Space Physics, 96 (A5):7657-7688, 1991. ISSN 2156-2202. doi: 10.1029/91JA00251. URL http://dx.doi.org/10.1029/91JA00251.

A. Higashikawa, T. Nakamura, and T. Tsuda. Seasonal variation of gravity waves observed with an $\mathrm{OH}$ CCD imager at Shigaraki $\left(35^{\circ} \mathrm{N}, 136^{\circ} \mathrm{E}\right)$, Japan. Advances in Space Research, 24(5):561 - 564, 1999. ISSN 0273-1177. doi: http://dx.doi.org/10.1016/S0273-1177(99) 00201-X. URL http://www.sciencedirect.com/science/article/ pii/S027311779900201X. Mesopause Region Structure, Dynamics and Composition.

Peter Hoffmann, Erich Becker, Werner Singer, and Manja Placke. Seasonal variation of mesospheric waves at northern middle and high latitudes. Journal of Atmospheric and Solar-Terrestrial Physics, 72(14-15):1068 1079, 2010. ISSN 1364-6826. doi: http://dx.doi.org/10.1016/j.jastp.2010. 07.002. URL http://www.sciencedirect.com/science/article/pii/ S1364682610001987.

J. R. Holton and Xun Zhu. A further study of gravity wave induced drag and diffusion in the mesosphere. Journal of the Atmospheric Sciences, 41(18): 2653-2662, 1984. doi: 10.1175/1520-0469(1984)041<2653:AFSOGW $\rangle 2.0$. CO;2. URL http://dx.doi.org/10.1175/1520-0469(1984)041<2653: AFSOGW $>2.0 . \mathrm{CO} ; 2$.

J. T. Houghton. The stratosphere and mesosphere. Quarterly Journal of the Royal Meteorological Society, 104(439):1-29, 1978. ISSN 1477-870X. doi: 10.1002/qj.49710443902. URL http://dx.doi.org/10.1002/qj . 49710443902. 
Q. Li, J. Xu, J. Yue, W. Yuan, and X. Liu. Statistical characteristics of gravity wave activities observed by an oh airglow imager at Xinglong, in northern China. Annales Geophysicae, 29(8):1401-1410, 2011a. doi: 10.5194/angeo-29-1401-2011. URL http://www. ann-geophys.net/29/ $1401 / 2011 /$.

Zhenhua Li, Alan Z. Liu, Xian Lu, Gary R. Swenson, and Steven J. Franke. Gravity wave characteristics from oh airglow imager over Maui. Journal of Geophysical Research: Atmospheres, 116(D22):n/a-n/a, 2011b. ISSN 2156-2202. doi: 10.1029/2011JD015870. URL http://dx.doi.org/10. 1029/2011JD015870.

R. S. Lindzen. Turbulence and stress owing to gravity-wave and tidal breakdown. Journal of Geophysical Research-Oceans and Atmospheres, 86(C10), 9707-9714, 1981. doi: 10.1029/JC086iC10p09707.

Alan Z. Liu and Gary R. Swenson. A modeling study of $\mathrm{O}_{2}$ and $\mathrm{OH}$ airglow perturbations induced by atmospheric gravity waves. Journal of Geophysical Research: Atmospheres, 108(D4):n/a-n/a, 2003. ISSN 21562202. doi: 10.1029/2002JD002474. URL http://dx.doi.org/10.1029/ 2002JD002474.

Charles McLandress, Gordon G. Shepherd, Brian H. Solheim, Mark D. Burrage, Paul B. Hays, and Wilbert R. Skinner. Combined mesosphere/thermosphere winds using windii and hrdi data from the upper atmosphere research satellite. Journal of Geophysical Research: Atmospheres, 101(D6):10441-10453, 1996. ISSN 2156-2202. doi: 10.1029/ 95JD01706. URL http://dx.doi.org/10.1029/95JD01706.

T. Nakamura, T. Aono, T. Tsuda, A. G. Admiranto, E. Achmad, and Suranto. Mesospheric gravity waves over a tropical convective region observed by oh airglow imaging in Indonesia. Geophysical Research Letters, 30(17):n/a-n/a, 2003. ISSN 1944-8007. doi: 10.1029/2003GL017619. URL http://dx.doi.org/10.1029/2003GL017619.

V. Lakshmi Narayanan and S. Gurubaran. Statistical characteristics of high frequency gravity waves observed by $\mathrm{OH}$ airglow imaging from Tirunelveli $\left(8.7^{\circ} \mathrm{N}\right)$. Journal of Atmospheric and Solar-Terrestrial Physics, 92(0):43 - 50, 2013. ISSN 1364-6826. doi: http://dx.doi.org/10.1016/j.jastp.2012. 
09.002. URL http://www.sciencedirect.com/science/article/pii/ S1364682612002234.

K. Nielsen, M. J. Taylor, P.-D. Pautet, D. C. Fritts, N. Mitchell, C. Beldon, B. P. Williams, W. Singer, F. J. Schmidlin, and R. A. Goldberg. Propagation of short-period gravity waves at high-latitudes during the macwave winter campaign. Annales Geophysicae, 24(4):1227-1243, 2006. doi: 10.5194/angeo-24-1227-2006. URL http://www. ann-geophys.net/ $24 / 1227 / 2006 /$.

P.-D. Pautet, M. J. Taylor, A. Z. Liu, and G. R. Swenson. Climatology of short-period gravity waves observed over northern Australia during the Darwin area wave experiment (DAWEX) and their dominant source regions. Journal of Geophysical Research: Atmospheres, 110(D3): n/a-n/a, 2005. ISSN 2156-2202. doi: 10.1029/2004JD004954. URL http://dx.doi .org/10.1029/2004JD004954.

Steven M. Smith, Michael Mendillo, Jeffrey Baumgardner, and Ronald R. Clark. Mesospheric gravity wave imaging at a subauroral site: First results from Millstone Hill. Journal of Geophysical Research: Space Physics, 105 (A12):27119-27130, 2000. ISSN 2156-2202. doi: 10.1029/1999JA000343. URL http://dx.doi.org/10.1029/1999JA000343.

Susan Solomon, R. R. Garcia, and M. E. McIntyre. Current understanding of mesospheric transport processes [and discussion]. Philosophical Transactions of the Royal Society of London. Series A, Mathematical and Physical Sciences, 323(1575):655-666, 1987. doi: 10.1098/rsta.1987.0112. URL http://rsta.royalsocietypublishing.org/content/323/1575/ 655. abstract.

S. Suzuki, K. Shiokawa, Y. Otsuka, T. Ogawa, and P. Wilkinson. Statistical characteristics of gravity waves observed by an all-sky imager at Darwin, Australia. Journal of Geophysical Research: Atmospheres, 109(D20):n/an/a, 2004. ISSN 2156-2202. doi: 10.1029/2003JD004336. URL http: //dx.doi.org/10.1029/2003JD004336.

S. Suzuki, K. Shiokawa, K. Hosokawa, K. Nakamura, and W. K. Hocking. Statistical characteristics of polar cap mesospheric gravity waves observed 
by an all-sky airglow imager at Resolute Bay, Canada. Journal of Geophysical Research: Space Physics, 114(A1):n/a-n/a, 2009a. ISSN 21562202. doi: 10.1029/2008JA013652. URL http://dx.doi.org/10.1029/ 2008JA013652.

S. Suzuki, K. Shiokawa, A. Z. Liu, Y. Otsuka, T. Ogawa, and T. Nakamura. Characteristics of equatorial gravity waves derived from mesospheric airglow imaging observations. Annales Geophysicae, 27(4):1625-1629, 2009b. doi: 10.5194/angeo-27-1625-2009. URL http://www. ann-geophys .net/ $27 / 1625 / 2009 /$.

J. Tang, G. R. Swenson, A. Z. Liu, and F. Kamalabadi. Observational investigations of gravity wave momentum flux with spectroscopic imaging. Journal of Geophysical Research: Atmospheres, 110(D9):n/a-n/a, 2005. ISSN 2156-2202. doi: 10.1029/2004JD004778. URL http://dx.doi.org/ 10.1029/2004JD004778.

Jing Tang, Alan Z. Liu, and Gary R. Swenson. High frequency gravity waves observed in $\mathrm{OH}$ airglow at Starfire Optical Range, NM: Seasonal variations in momentum flux. Geophysical Research Letters, 29(20):27-127-4, 2002. ISSN 1944-8007. doi: 10.1029/2002GL015794. URL http: //dx.doi.org/10.1029/2002GL015794.

M. J. Taylor and F. J. Garcia. A two-dimensional spectral analysis of short period gravity waves imaged in the $\mathrm{OI}(557.7 \mathrm{~nm})$ and near infra red $\mathrm{OH}$ nightglow emissions over Arecibo, Puerto Rico. Geophysical Research Letters, 22(18):2473-2476, 1995. ISSN 1944-8007. doi: 10.1029/95GL02491. URL http://dx.doi.org/10.1029/95GL02491.

M. J. Taylor, E. H. Ryan, T. F. Tuan, and R. Edwards. Evidence of preferential directions for gravity wave propagation due to wind filtering in the middle atmosphere. Journal of Geophysical Research: Space Physics, 98 (A4):6047-6057, 1993. ISSN 2156-2202. doi: 10.1029/92JA02604. URL http://dx.doi.org/10.1029/92JA02604.

M. J. Taylor, W. R. Pendleton, S. Clark, H. Takahashi, D. Gobbi, and R. A. Goldberg. Image measurements of short-period gravity waves at equatorial latitudes. Journal of Geophysical Research: Atmospheres, 102(D22):2628326299, 1997. ISSN 2156-2202. doi: 10.1029/96JD03515. URL http: //dx.doi.org/10.1029/96JD03515. 
F. Vargas. Investigação do fluxo de momento das ondas de gravidade na alta atmosfera através da aeroluminescência (Investigation of gravity wave momentum fluxes in the upper atmosphere derived from airglow). $\mathrm{PhD}$ thesis, Instituto Nacional de Pesquisas Espaciais (National Institute for Space Research), INPE, Sao Jose dos Campos, Brazil, 2007. URL http: //urlib.net/sid.inpe.br/mtc-m17@80/2007/07.18.12.20.

F. Vargas, D. Gobbi, H. Takahashi, and L. M. Lima. Gravity wave amplitudes and momentum fluxes inferred from $\mathrm{OH}$ airglow intensities and meteor radar winds during spreadfex. Annales Geophysicae, 27(6):2361-2369, 2009. doi: 10.5194/angeo-27-2361-2009. URL http: //www . ann-geophys . net $/ 27 / 2361 / 2009 /$.

Fabio Vargas, Gary Swenson, Alan Liu, and Delano Gobbi. O $\left({ }^{1} \mathrm{~S}\right), \mathrm{OH}$, and $\mathrm{O}_{2}$ (b) airglow layer perturbations due to agws and their implied effects on the atmosphere. Journal of Geophysical Research: Atmospheres, 112 (D14):n/a-n/a, 2007. ISSN 2156-2202. doi: 10.1029/2006JD007642. URL http://dx.doi.org/10.1029/2006JD007642.

R.L. Walterscheid, J.H. Hecht, R.a. Vincent, I.m. Reid, J. Woithe, and M.P. Hickey. Analysis and interpretation of airglow and radar observations of quasi-monochromatic gravity waves in the upper mesosphere and lower thermosphere over Adelaide, Australia $\left(35^{\circ} \mathrm{S}, 138^{\circ} \mathrm{E}\right)$. Journal of Atmospheric and Solar-Terrestrial Physics, 61(6):461 - 478, 1999. ISSN 1364-6826. doi: http://dx.doi.org/10.1016/S1364-6826(99) 00002-4. URL http://www.sciencedirect.com/science/article/pii/ S1364682699000024.

Jia Yue and Han-Li Liu. Fast meridional transport in the lower thermosphere by planetary-scale waves. Journal of Atmospheric and Solar-Terrestrial Physics, 72(18):1372 - 1378, 2010. ISSN 1364-6826. doi: http://dx.doi. org/10.1016/j.jastp.2010.10.001. URL http://www.sciencedirect.com/ science/article/pii/S1364682610003044.

S. D. Zhang, C. M. Huang, K. M. Huang, F. Yi, Y. H. Zhang, Y. Gong, and Q. Gan. Spatial and seasonal variability of medium- and highfrequency gravity waves in the lower atmosphere revealed by US radiosonde data. Annales Geophysicae, 32(9):1129-1143, 2014. doi: 10.5194/angeo-32-1129-2014. URL http://www.ann-geophys.net/32/ $1129 / 2014 /$. 
Xun Zhu, P. K. Swaminathan, J. H. Yee, D. F. Strobel, and D. Anderson. A globally balanced two-dimensional middle atmosphere model: Dynamical studies of mesopause meridional circulation and stratospheremesosphere exchange. Journal of Geophysical Research: Atmospheres, 102 (D11):13095-13112, 1997. ISSN 2156-2202. doi: 10.1029/97JD00459. URL http://dx.doi.org/10.1029/97JD00459.

Xun Zhu, Jeng-Hwa Yee, William H. Swartz, Elsayed R. Talaat, and Lawrence Coy. A spectral parameterization of drag, eddy diffusion, and wave heating for a three-dimensional flow induced by breaking gravity waves. Journal of the Atmospheric Sciences, 67(8):2520-2536, 2014/06/04 2010. doi: 10.1175/2010JAS3302.1. URL http://dx.doi.org/10.1175/ 2010JAS3302.1. 
Figure 1: (a) GW drag direction around the globe during the northern winter (southern summer) (b) GW drag direction around the globe during the northern summer (southern winter). 
Figure 2: Altitude vs. latitude cross-section of the (a) zonal and (b) meridional background wind provide by the Horizontal Wind Model 93 (HWM93) (Hedin et al., 1991). The following inputs were used in the model run: year: 2009, doy: 180 (June 29), latitude: $30.3^{\circ} \mathrm{S}$, longitude: $70.7^{\circ} \mathrm{W}$, local solar time: $20.2 \mathrm{~h}$ (00:00 UT), F107: 150, and Ap: 4) 

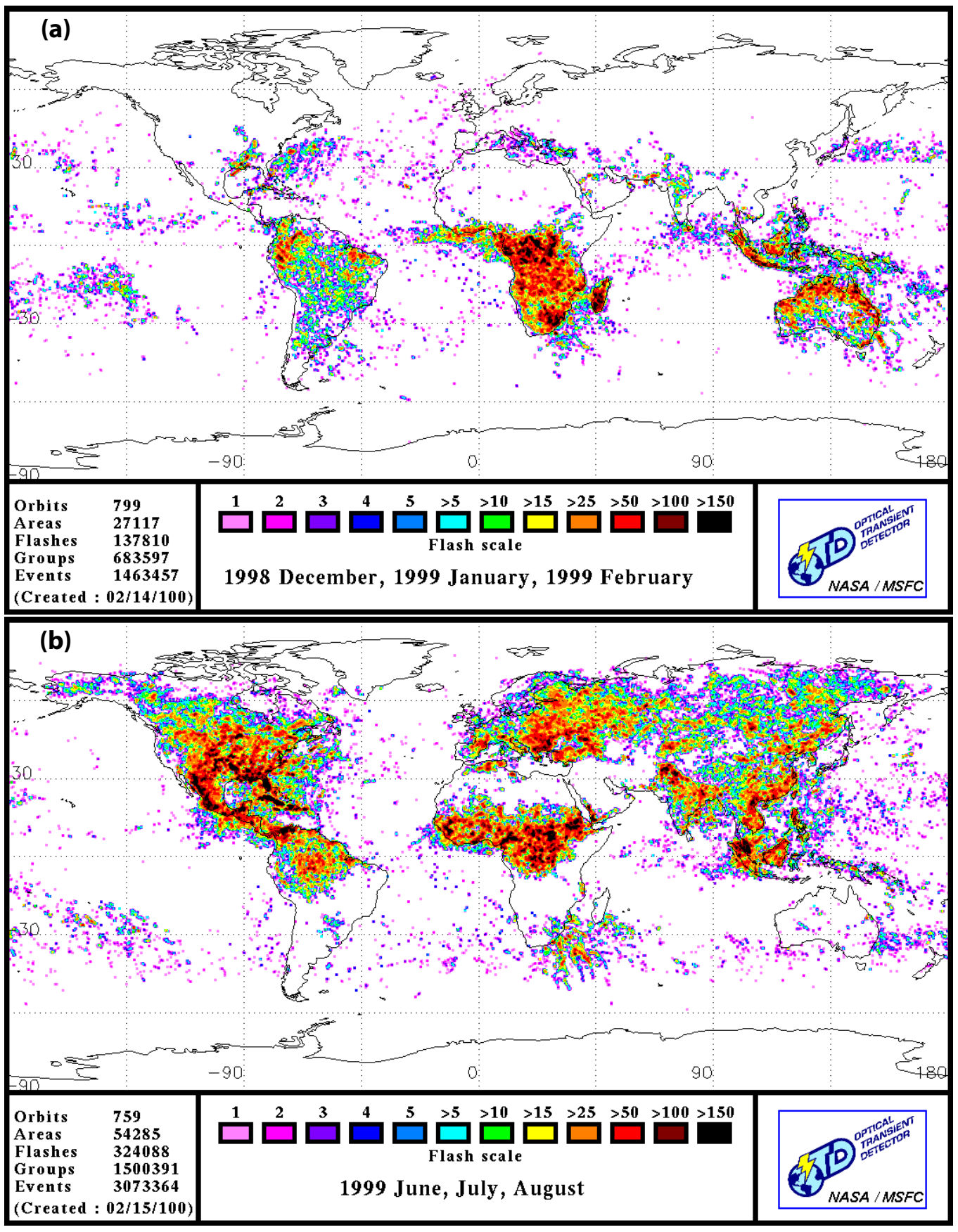

Figure 3: Lightning activity for the northern (a) winter and (b) summer in 1999 provided by the Optical Transient Detector (OTD) satellite, lunched by the National Aeronautics and Space Administration, NASA. 


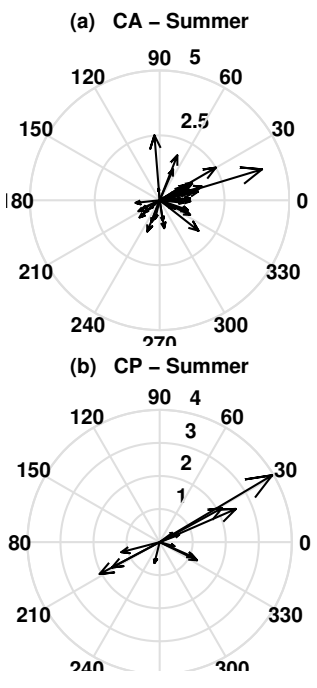

(c) ALO - Summer

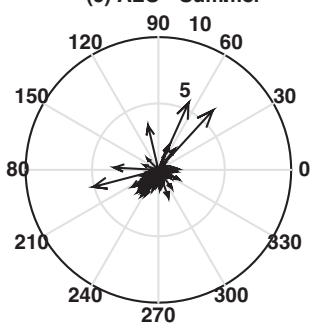

(a) CA - Winter

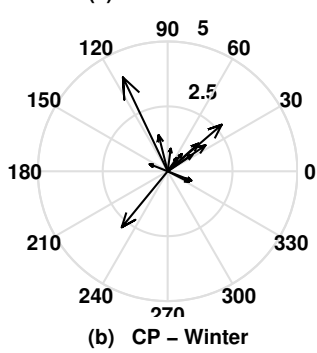

$90 \quad 5$

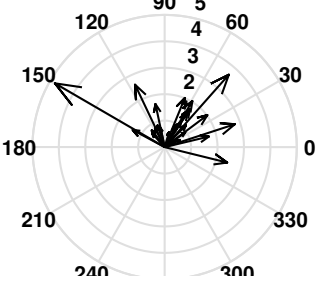

(c) ALO - Winter

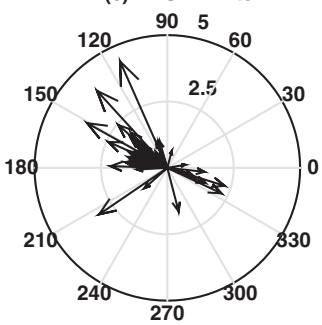

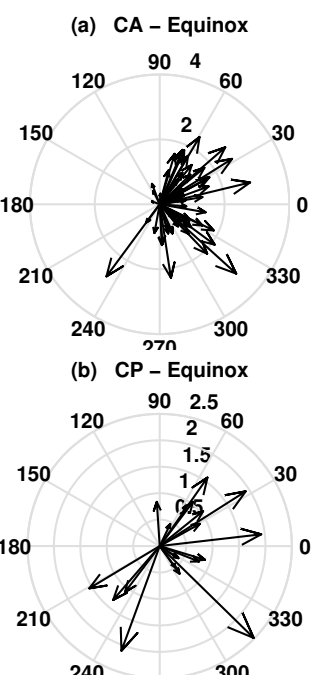

(c) ALO - Equinox



Figure 4: Flux Divergence vs. Propagation Direction of GW observed between $\mathrm{OH}$ and $\mathrm{O}\left({ }^{1} S\right.$ ) layers in (a) Cariri, (b) Cachoeira Paulista, and (c) Cerro Pachon. Arrows have units of $\mathrm{m} / \mathrm{s} /$ hour. 


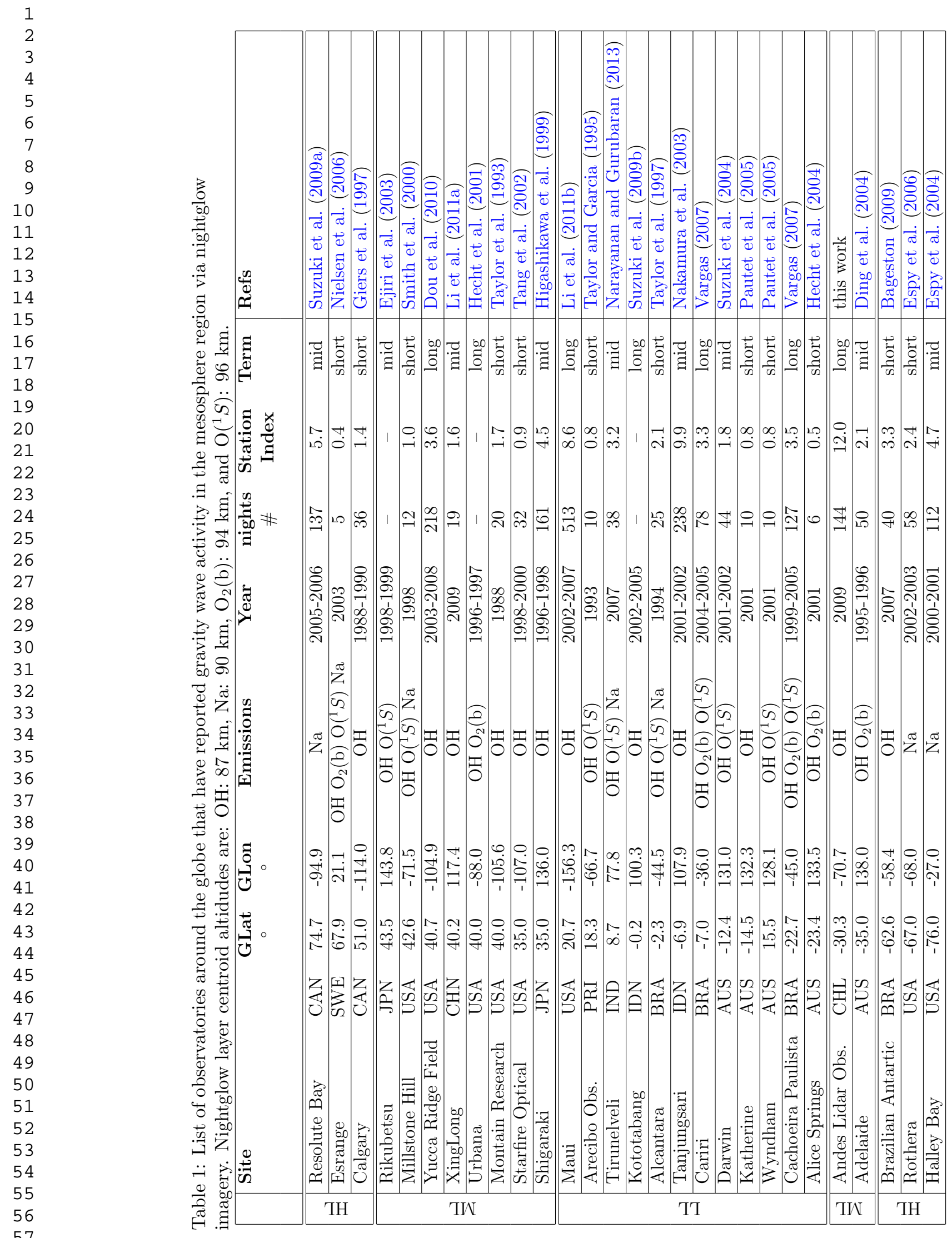


Table 2: Meridional component vector of GW drag (m/s/day) from nightglow imagery. High uncertainty data were omitted.

\begin{tabular}{lrrr}
\hline Station & Summer & Winter & Equinox \\
\hline Cariri & $-0.7 \pm 0.4$ & $10.0 \pm 1.7$ & $1.9 \pm 0.6$ \\
Cachoeira Paulista & - & $16.1 \pm 1.6$ & - \\
Cerro Pachon & $-6.9 \pm 0.3$ & $3.5 \pm 0.2$ & - \\
\hline Weighted Mean & $-4.6 \pm 0.2$ & $3.8 \pm 0.2$ & $1.9 \pm 0.6$ \\
\hline
\end{tabular}

